\title{
Adorno's critique of work in market society
}

Article

Published Version

Open Access

Reeves, C. and Sinnicks, M. (2022) Adorno's critique of work in market society. Business Ethics Journal Review, 10 (1). pp. 1-7. ISSN 2326-7526 doi: https://doi.org/10.12747/j1j01 Available at https://centaur.reading.ac.uk/102216/

It is advisable to refer to the publisher's version if you intend to cite from the work. See Guidance on citing.

Identification Number/DOI: https://doi.org/10.12747/j1j01

$<$ https://doi.org/10.12747/j1j01>

Publisher: Philosophy Documentation Center

All outputs in CentAUR are protected by Intellectual Property Rights law, including copyright law. Copyright and IPR is retained by the creators or other copyright holders. Terms and conditions for use of this material are defined in the End User Agreement.

\section{www.reading.ac.uk/centaur}

\section{CentAUR}

Central Archive at the University of Reading

Reading's research outputs online 


\title{
ADORNO'S CRITIQUE OF WORK IN MARKET SOCIETY
}

Craig Reeves and Matthew Sinnicks ${ }^{1}$

AN INVITED RESPONSE TO Jaakko Nevasto (2021), “Adorno's Critical Moral Philosophy and Business Ethics,” Bus Ethics J Rev 9(7): 40-46, https://doi.org/10.12747/j1i07

\begin{abstract}
Jaakko Nevasto has offered a number of thoughtful criticisms of our attempt to show that Adorno's work can fruitfully be brought to bear on topics in business ethics. After welcoming his constructive clarifications, we attempt to defuse Nevasto's main objections and defend our application of Adorno, focusing in particular on the topics of moral epistemology, needs, and the possibility of genuine activity - and thus good work - within capitalist society.
\end{abstract}

KANT SAYS THAT masturbation "obviously runs counter to the ends of humanity, and conflicts, even, with animal nature” (Kant 1997: 161). As uptight as contemporary Kantians can sometimes seem, it is at least conceivable that they do not accept this and other aspects of Kant's ethical thought. Similarly, it's perfectly legitimate to draw on Adorno's ethical thought without restricting oneself to claims he would have endorsed, as we tried to do in our recent paper (Reeves and Sinnicks 2021). Nevertheless, we believe we can respond to Nevasto's thoughtful objections on good Adornian grounds, in furtherance of our shared aim to elucidate "the relevance of Adorno's thought to new directions in business ethics” (Nevasto 2021: 41). In what follows we address three key points from Nevasto's discussion:

${ }^{1}$ Birkbeck College, London and University of Reading (respectively).

Email: c.reeves@bbk.ac.uk, m.sinnicks@henley.ac.uk 
1) moral epistemology and societal evil, 2) true and false needs, and 3) genuine activity and good work.

\section{Moral Epistemology and Societal Evil}

Nevasto helpfully clarifies an issue we had to gloss over, making explicit a step of Adorno's argument that we left implicit: that 'wrong life' makes a right or good life impossible because acting well requires moral insights which require appropriately tutored impulses, yet the structures and institutions of wrong life do not provide an adequate context for the proper tutoring of impulses, nor for the reflective practical exercise of such impulses even when they are possible.

We did, however, point out that part of why wrong life "cannot be lived rightly” is that its institutions mistutor our impulses:

insofar as they have internalised identity thinking, individuals become trapped in a distorting pattern of thinking that prevents them from seeing or being guided by normatively relevant aspects of others and of themselves... they can neither think nor act autonomously (Reeves and Sinnicks 2021: 504).

Nevasto (2021: 41) aims to clarify why this means that "the moral adjective "evil" can apply to societies in their entirety, [and] why these problems pose a fundamental challenge to business ethics." This is helpful, since it is true that we didn't properly unpack Adorno's application of the category 'evil' to societies as a whole (in part because Adorno's conception of evil is so complex and unusual (see Dews 2008), while his account of our societies as damaged, unfree and false anyway offers plenty to be going on with).

Nevertheless, our "discussion of social roles and the psychological disintegration they arguably precipitate" (Nevasto 2021: 4243) showed how these and "the fragmented role of the actor" (Reeves and Sinnicks 2021: 510) tend to undermine the possibility of moral agency, autonomy or rational health. And we illustrated the widereaching implications of such analyses for business ethics by critiquing the ideologies of management's self-understanding, which exhibit the dialectical dead-ends Adorno found rife throughout modern thought (Reeves and Sinnicks 2021: 510-513).

So, while we disagree with the suggestion that our account is "short of philosophical resources" (Nevasto 2021: 41), some of these 
resources remained only implicit, and we welcome Nevasto's making explicit some important steps of the argument.

\section{True and False Needs}

Nevasto raises important questions about the interpretation of Adorno's concepts of true and false needs. He (2021: 42) points out that

Adorno (2017: 103) denies precisely a polar distinction between true and false needs: "No neat distinction can be made between a need proper to humanity and one that would be a consequence of repression" and further still that all existing "needs are conglomerates of truth and falsehood".

Indeed - but what exactly does this mean? It can't be that existing needs combine truth and falsehood in the same way and to the same degree. The passages preceding the line Nevasto quotes read:

The faulty consciousness of their needs aims at things not needed by subjects, human beings who have come of age... A thought without a need would be like nothing, but a thought based on a need becomes confused if our conception of the need is purely subjective. What would be true is the thought that wants the right thing (Adorno 1973: 92-93).

This suggests that false needs not only, in their falsity, tell us something true about the badness of our social world, but, moreover, are distortions, misdirections of true needs into the 'wrong form' onto the wrong objects, albeit wrong objects that are really needed by subjects trying to cope in and adapt to a privative social world.

And Adorno (1973: 93) is not as reluctant to concretely diagnose false needs as Nevasto implies: he cites "the primitive wish-fulfilments [of] the culture industry", and "the need for something solid" which "inspires the ontologies", and we gave numerous other examples (e.g., Reeves and Sinnicks 2021: 508, 512).

The true/false needs distinction calls for further exploration, and Nevasto is right to raise the issue, but it is important to note that false needs are not the only problem or focus of our Adornian account. Not all existing needs are false - many true needs are not suppressed but simply go consciously unfulfilled in experienced suffering. The 'boredom' which is the appropriate response to the 'objective dullness' of most modern work is one such example (Reeves and Sinnicks 2021: 515). 


\section{Genuine Activity and Good Work}

Nevasto claims that, in introducing the notions of 'good work' and 'genuine activity', we revert from Adorno's Critical Theory to traditional moral philosophy, for

Such ideas act as the critical fork against which reality is held to account .... At this juncture the argument does not, methodologically speaking, proceed as a critical theory, but as moral philosophy which understands its activity as assessing the world in light of a normative ontology (Nevasto 2021: 44).

We obviously failed to make ourselves clear on this, and appreciate the opportunity to do so now.

The idea of the unrestricted standpoint of flourishing, the 'standpoint of redemption', is formal not substantive. We don't posit this 'standpoint' as a substantive normative conception from which to criticise. Since it corresponds to an unrealised potential, this 'standpoint' is not available to us as a substantive normative lens.

Nevertheless, it must be presupposed as the conceptual backdrop for critique to make sense. That critique is primarily negative proceeding from diagnoses of what seems to be wrong now, assuming that we can diagnose what is wrong directly, without a substantive positive standard by which to judge. This is why suffering has a central role in Adorno's ethics: suffering prima facie manifests ailing, and we can diagnose such ailing without substantive knowledge of flourishing (see Freyenhagen 2013: ch. 8; Reeves 2016). Yet the concept of ailing is intelligible only on the formal assumption of a potential, though as-yet-unrealised, "unrestricted standpoint of . . . human flourishing” (Reeves and Sinnicks 2021: 518).

Hence, our consideration of potentially good work as 'genuine activity' is no reversion to a traditional moral philosophy that judges the bad against the positively known good. Quite the opposite: our Adorno diagnoses and explains what seem examples of suffering from bad work now, and of false needs by which subjects cope with that suffering. From these negative diagnoses, however, certain hypotheses present themselves. If bad work is characteristically boring and meaningless, governed by heteronomous ends and form, good work would, plausibly, involve autonomy, creativity, and orientation to human flourishing - and the least bad work available now would most closely approximate those qualities. 
Genuine activity isn't a canon "against which reality is held to account," but a negative extrapolation from the badness of work in wrong life. Similarly, Adorno's criticisms of false needs proceed not from a prior conception of true needs, but from explanatory interpretations of existing needs in relation of the social world that generates them: needs which seem to exist primarily to allow subjects to cope with social mechanisms which are systematically blind to human needs as such, are likely to be false.

Nevasto claims our appeal to 'genuine activity' generates a dilemma: "If capitalism is merely "some way short" of the genuine human form, it does not sound all that radical, or evil... And if we maintain the radical evil thesis, the restriction of it to cover only performative work and management - but not philosophy and art - is an arbitrary one.” (2021: 44) This mischaracterises our position. We say not that capitalism is 'merely some way short' of realising 'the genuine human form', but that even the rare cases of potentially good work are, in capitalist societies, doomed to fall 'some way short' qua genuine activity:

Forms of genuine activity... approximate kinds of genuine experiences that come close to fulfilling genuine needs for creative activity and granting genuinely autonomous experience, even if the wider context ensures that they will fall some way short of this telos. (Reeves and Sinnicks 2021: 516)

This is no threat to the radical evil thesis; it simply recognises wrong life spoils even essentially good things.

Many kinds of contemporary work, we argue, are so essentially impoverished that the thought that their essence is being undermined from without by exchange society wouldn't make sense (2021: 517518). Part of what is so bad about our social world is that it proliferates such kinds of essentially impoverished work. But we don't 'arbitrarily' exclude philosophy and art from the radical evil thesis: philosophy has, "under the social pressures of the identitarian reification of thinking, largely collapsed into resignation and abdication of its proper telos" (2021: 516), while art has largely succumbed to "contamination by exchange society and subsumption by the culture industry" (2021: 516). That is, even genuine activities, already the exceptions, are deformed by the pressures of exchange society. 
This point gets its force from the intuitively obvious fact that some kinds of work involve something closer to genuine activity than others. To understand this facet of the badness of our social world, we need the distinction between genuine and privative activity. This distinction is often explicit in Adorno-for example, in his critical comments on 'hobbies' (2005b: 168), and his confession of guilt about being someone able to "seek out and arrange his work according to his own intentions" (2005b: 169). Such guilt is intelligible only if there are intrinsically better and worse forms of work, even in wrong life. The radical evil thesis by no means conflicts with the suggestion that, within our bad social world, work is a lot worse for some than for others. The gross disparities in life opportunities and experiences endemic to modern societies are another aspect of their badness.

$*$

To conclude, while we are unmoved by some of Nevasto's criticisms of our account, we nevertheless find much of value in his clarificatory remarks, appreciate such serious engagement with our work, and look forward to continuing the conversation.

Received 18 October 2021 / Posted 31 January 2021

\section{REFERENCES}

Adorno, T. W. 1973. Negative Dialectics. London: Routledge.

Adorno, T. W. 2005a. Minima Moralia. London: Verso (original ed., 1951).

Adorno, T. W. 2005b. Critical Models: Interventions and Catchwords. New York: Columbia University Press (original works contained in the volume published 1963, 1969).

Dews, P. 2008. The Idea Of Evil. Oxford: Blackwell.

Freyenhagen, F. 2013. Adorno's Practical Philosophy: Living Less Wrongly. Cambridge: Cambridge University Press, https://doi.org/10.1017/CBO9781139567763

Kant, I. 1997. Lectures on Ethics. Cambridge: Cambridge University Press, https://doi.org/10.1017/CBO9781107049512

Nevasto, J. 2021. “Adorno’s Critical Moral Philosophy and Business Ethics,” Bus Ethics J Rev 9(7): 40-46, https://doi.org/10.12747/j1i07 
Reeves, C. 2016. “Beyond the Postmetaphysical Turn,” J Crit Realism 15(3): 217-244, https://doi.org/10.1080/14767430.2016.1171666

Reeves, C. and M. Sinnicks. 2021. "Business Ethics from the Standpoint of Redemption: Adorno on the Possibility of Good Work.” Bus Ethics $\mathbf{Q}$ 31(4): 500-523, https://doi.org/10.1017/beq.2020.45 